Mironov V. 2003. Larentiinae II (Perizomini and Eupitheciini // The Geometrid Moths of Europe. Volume 4 / A. Hausmann. Apollo Books, Stenstrup. 463 p.

Skou P., Sihvonen P. 2015. Subfamily Ennominae I (Abraxini, Apeirini, Baptini, Caberini, Campaeini, Cassymini, Colotoini, Ennomini, Epionini, Gnophini (part), Hypochrosini, Lithinini, Macariini, Prosopolophini, Theriini, and 34 species of uncertain tribus association) // The Geometrid Moths of Europe. Volume 5 / A. Hausmann. Brill, Leiden. 657 p.

\title{
GEOMETROIDEA IN TVER REGION
}

\author{
A.G. Korobkov' ${ }^{1}$, V.G. Mironov ${ }^{2}$ \\ ${ }^{1}$ Udomelsky Forest Area of the Tver region, Udomlya (Tver region) \\ ${ }^{2}$ Zoological Institute RAS, Saint-Petersburg
}

The article provides an annotated list of 240 species of Geometroidea (Geometroidea: Uraniidae, Geometridae) identified in the Tver Region. Keywords: Geometroidea, Uraniidae, Geometridae, Tver Region, Russia.

\section{Об авторах:}

КОРОБКОВ Александр Григорьевич - начальник Удомельского отдела лесного хозяйства ГКУ «Удомельское лесничество Тверской области», Тверская область, Удомля, ул. Попова, д. 11.

МИРОНОВ Владимир Георгиевич - кандидат биологических наук, старший научный сотрудник, ФГБУН Зоологический институт РАН, 199034, Санкт-Петербург, Университетская наб., д. 1.

Коробков А.Г. Пяденицеобразные чешуекрылые (Geometroidea) в Тверской области / А.Г. Коробков, В.Г. Миронов // Вестн. ТвГУ. Сер.: Биология и экология. 2020. № 2(58). C. 27-54.

\section{ВЛИЯНИЕ КРАТКОВРЕМЕННОГО ХОЛОДОВОГО ВОЗДЕЙСТВИЯ НА ГЕМАТОЛОГИЧЕСКИЕ ПОКАЗАТЕЛИ ПОЛЕВКИ-ЭКОНОМКИ (MICROTUS OECONOMUS PALLAS)}

\footnotetext{
* Работа выполнена в рамках темы НИР Института биологии ФИЦ Коми НЦ УрО РАН, ГЗ № АAАA-A18-118011190102-7.
} 


\author{
А.Г. Кудяшева, А.В. Ермакова, О.В. Раскоша \\ Институт биологии ФИЦ Коми НЦ УрО РАН, Сыктывкар
}

Проведено изучение воздействия низкой температуры $\left(-5^{0} \mathrm{C}\right)$ в течение двух часов на гематологические показатели самцов полевок-экономок (Microtus oeconomus Pallas) разного возраста (2, 4 и 10 месяцев). Обнаружена зависимость проявления эффекта от возраста животных. В большей степени на общее переохлаждение реагировали полевки старшей возрастной группы. Установлено, что действие холода вызывает умеренную лейкопению и лимфопению у половозрелых животных (4 и 10 месяцев), а также понижение содержания тромбоцитов в периферической крови у 10 месячных самцов. Полученные данные свидетельствуют о чувствительности показателей периферической крови самцов полевок-экономок к кратковременному действию низкой температуры и являются отражением неспецифичных клеточных реакций.

Ключевые слова: холод, неспецифическая реакиия, стресс, периферическая кровь, полевка-экономка, возраст.

DOI: $10.26456 /$ vtbio148

Введение. Холод является одним из естественных экологических факторов внешней среды, действующих на человека и животных в условиях Севера. Негативное воздействие холодового фактора на организм может быть компенсировано в случае отсутствия глубокого повреждения тканевых структур и серьезных физиологических сдвигов (Бойко, 2005; Солонин и др., 2011), которые, однако, в той или иной степени могут отразиться на количественном и качественном составе крови (Гармаева и др., 2019). Известно, что одни и те же воздействия у животных различных возрастных групп вызывают разные реакции (Жуков и др., 1995; Абрашова и др., 2013). Учитывая важную роль системы крови в формировании ответной реакции организма на воздействие стрессовых факторов, цель работы состояла в выявлении количественных изменений клеточного состава крови у мышевидных грызунов разного возраста после кратковременного действия низких температур.

Методика. В эксперименте при моделировании однократного холодового воздействия использованы 47 самцов полевок-экономок, являющихся потомками животных, отловленных в Ухтинском районе

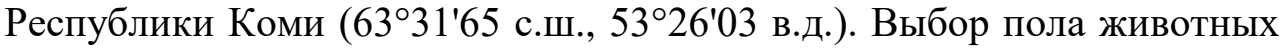
был обусловлен необходимостью получения стабильных результатов, исключая влияние циклических изменений, характерных для организма самок. Всех животных содержали в индивидуальных клетках на полноценной диете со свободным доступом к воде и пище в виварии 
Института биологии (УНУ «Научная коллекция экспериментальных животных»; http://www.ckp-rf.ru/usu/471933), в стандартных условиях соответствующих требованиям санитарно-эпидемиологических правил (СП 2.2.1.3218-14). Следует отметить, что этот вид полевок успешно размножался в условиях вивария. При работе с дикими животными руководствовались рядом требований и рекомендаций (Раскоша и др., 2016). Нами было показано, что полевка-экономка является удобным модельным объектом для изучения антропогенного загрязнения среды (Кудяшева и др., 2016; Раскоша, 2018). Однако в природных условиях точная оценка возраста животных сопряжена с объективными трудностями, которые можно избежать при проведении исследований в виварии - строго фиксируя дату рождения особей, контролируя интенсивность их роста, изменения в половой сфере и др.

В зависимости от возраста полевки-экономки были разделены на три варианта эксперимента, в каждом из которых случайным образом формировали опытную и контрольную группы (по 7-8 особей). В варианте эксперимента I использовали неполовозрелых полевокэкономок (возраст 2 мес.), в варианте II - половозрелых репродуктивно активных животных (возраст 4 мес.) и в варианте III - половозрелых полевок зрелого возраста со сниженной интенсивность размножения (10 мес.). В каждом варианте эксперимента разброс животных по массе не превышал $10 \%$. Самцов всех опытных групп содержали в течение двух часов в индивидуальных клетках, ограничивающих движение, при температуре $-5^{0} \mathrm{C}$ с соблюдением адекватных условий влажности и вентиляции. Такая температура для полевок является экстремальной, так как в естественной среде обитания даже в холодное время года под снежным покровом формируются условия, исключающие влияние низких температур внешней среды. Кроме того, полевки-экономки ведут активный подснежный образ жизни, способствующий поддержанию теплового баланса (Прокопьев, 2014). Контрольные группы животных соответствовали по возрасту опытным, находились в идентичных условиях при комнатной температуре $\left(+20^{0} \mathrm{C}\right)$. Из эксперимента животных выводили путем верхней декапитации с 10-11 часов утра с соблюдением требований Международных принципов Хельсинской декларации о гуманном отношении к животным для экстирпации органов (World Medical..., 2002). Гематологические показатели определяли в цельной крови с антикоагулянтом сразу после декапитации животных. В пробах крови на гематологическом анализаторе MicroCC-20Plus (ветеринарная версия, High Tehcnology, Inc, США) выявляли количество эритроцитов и гемоглобина, общее содержание лимфоцитов, количество лейкоцитов, гранулоцитов, а также тромбоцитов, анализировали показатель MID (средние клетки), объединяющий смесь моноцитов, эозинофилов, базофилов и незрелых 
клеток. Дифференциация и подсчет клеток крови в используемом анализаторе основан на принципе кондуктометрии (колориметрии для измерения гемоглобина). Результаты обрабатывали с применением вариационной статистики, данные представлены в виде средних значений и их ошибок. Достоверность различий между значениями контрольных и опытных групп по исследуемым показателям оценивали с применением $\mathrm{t}$ критерия Стьюдента.

Результатьи и обсуждение. В результате проведенного исследования выявлено, что в периферической крови контрольных половозрелых самцов полевок-экономок в оптимальных условиях температуры по сравнению с нормами, установленными для человека (Абрашова и др., 2013), наблюдается повышенное содержание лейкоцитов и эритроцитов, а также отличие в системе гемостаза - выше количество тромбоцитов, что сопровождалось пониженным содержанием лимфоцитов и гранулоцитов. У лабораторных беспородных мышей и крыс, также как и у полевок-экономок, отмечается повышенное содержание эритроцитов и тромбоцитов, однако в лейкоцитарной формуле лимфоциты преобладали по сравнению с нормами, установленными для человека (Гольдберг и др., 1973; Абрашова и др., 2013). Следует отметить, что в целом показатели периферической крови контрольных полевок-экономок, разведенных в виварии, имели сходные значения, описанные ранее для животных этого вида, обитающих в условиях средне-таежной зоны (Материй и др., 2003).

Анализ полученных данных показал, что даже после кратковременного действия холодового фактора $\left(-5^{0} \mathrm{C}\right)$ происходит изменение количественного состава отдельных форменных элементов в крови опытных групп полевок относительно соответствующих контрольных значений. Установлено, что наиболее чувствительными к действию холода были лейкоциты и лимфоциты, обеспечивающие сохранение неспецифического и специфического клеточного иммунитета в ответ на воздействие стрессовых факторов разной природы (Ватутин, Ещенко, 2016). 
Вестник ТвГУ. Серия "Биология и экология". 2020. № 2 (58)
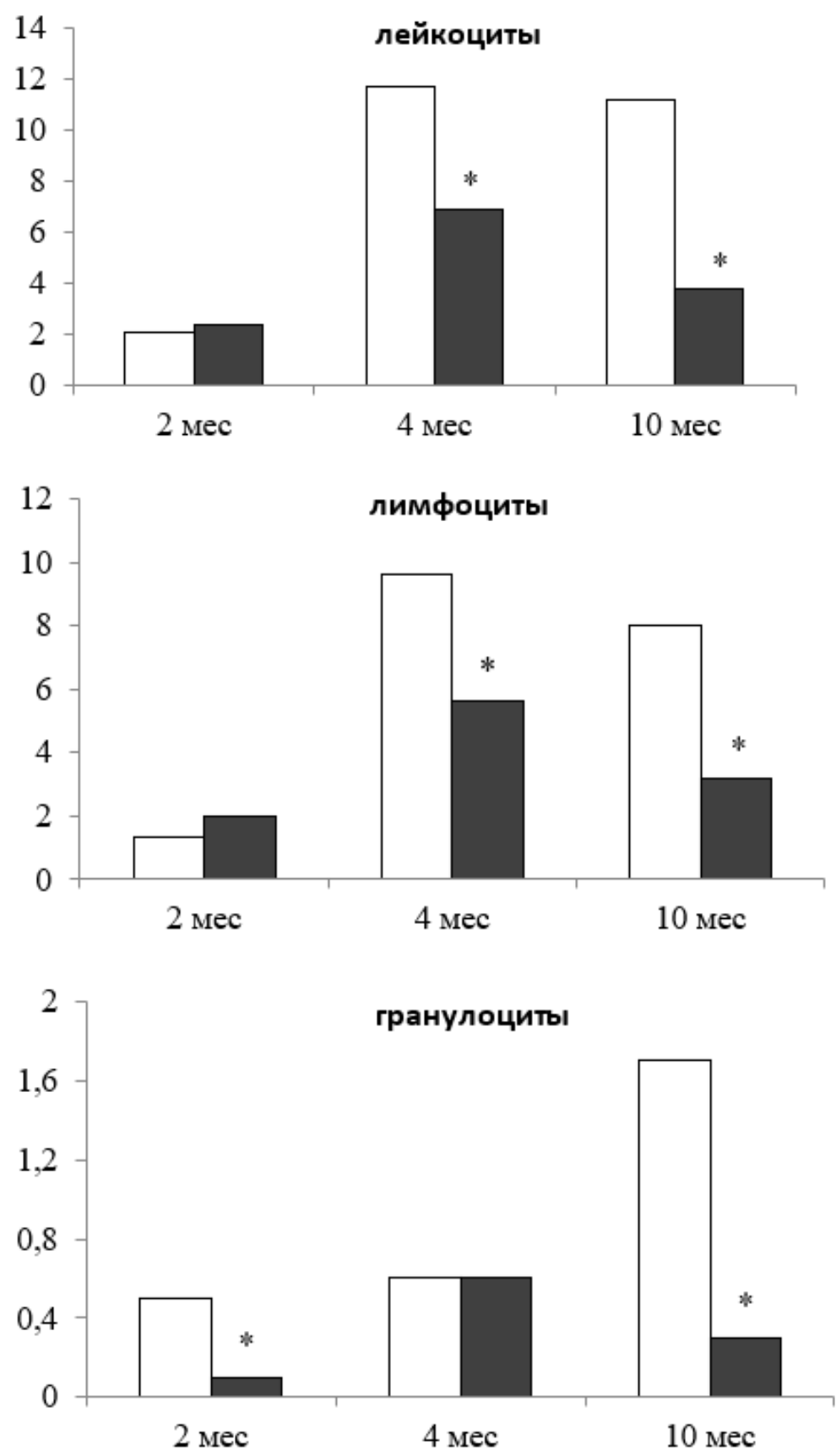

Рис. Показатели периферической крови (х109 $л)$ полевок-экономок разного возраста после кратковременного действия холода $\left(-5^{0} \mathrm{C}\right)$.

Различия с контролем статистически значимы при * $\mathrm{p} \leq 0,05$.

Обнаружено, что после действия холода общее число лейкоцитов в периферической крови статистически значимо уменьшалось, при этом в большей степени на переохлаждение 
реагировали полевки старшей возрастной группы (в 1,7 и 3,8 раза у II и III опытных групп, соответственно) (рис.). У неполовозрелых животных (I опытная группа) значимых различий с контролем по этому показателю не обнаружено. Снижение общего содержания лейкоцитов в периферической крови описано в исследованиях на животных из природных популяций, испытывающих неспецифическое действие радиационного фактора (Алексахин и др., 1990; Шилкова и др.,1999; Васильева и др., 2007). Аналогичные изменения количественных показателей клеток крови наблюдали и в экспериментах при действии разных физических факторов у лабораторных животных (Ажикова и др., 2016; Залесская и др., 2018; Гармаева и др., 2019). После нахождения полевок в условиях низкой температуры в пробах крови статистически значимо понижалось общее содержание лимфоцитов (у II и III опытных групп) и гранулоцитов (у I и III опытных групп), с более выраженным проявлением эффекта у животных старшего возраста. Схожую направленность изменений в периферической крови мелких млекопитающих отмечали при различных стрессовых воздействиях (Горизонтов и др., 1983; Елифанов и др., 2012; Соловьев и др., 2016; Тарахтий и др., 2016; Залеская и др., 2018), в том числе и после действия холода (Xу GZ et al., 2016; Гармаева и др., 2019). Показатель MID, объединяющий смесь моноцитов, эозинофилов, базофилов и незрелых клеток, также был ниже контрольных значений у особей II и III опытных групп (в $1,8(\mathrm{p} \leq 0,05)$ и 1,4 раза, соответственно). Кроме того, у животных старшей возрастной группы после воздействия холода в пробах крови выявлено статистически значимое понижение на $20 \%$ $(\mathrm{p} \leq 0,05)$ содержания тромбоцитов, у самцов других опытных групп этот показатель был в пределах нормы. По данным литературы уменьшение числа тромбоцитов при холодовом воздействии может быть связано с повышенным расходом этих форм клеток в воспалительных и репаративных процессах (Шаповалов и др., 2008). Показатели красной крови у полевок после переохлаждения не выходили за пределы контрольных значений (в соответствии с возрастом животных): содержание эритроцитов находилось в пределах от 9.0 до $13.3 \times 10^{12} /$ л, а уровень гемоглобина от 150,6 до 192,1 г/л. Высокая устойчивость показателей красной крови животных к действию повреждающих факторов отмечается и в других работах (Алексахин и др., 1990; Васильева и др., 2007; Тарахтий и др., 2016; Иванов и др., 2018; Залеская и др., 2018).

Заключение. Таким, образом, данные проведенного эксперимента, свидетельствуют о чувствительности показателей периферической крови самцов полевок-экономок к кратковременному действию низкой температуры $\left(-5^{\circ} \mathrm{C}\right)$ и являются отражением неспецифичных клеточных реакций на воздействие фактора 
физической природы. Выявлена зависимость выраженности эффекта в периферической системе клеток крови от возраста животных. Обнаружено, что действие холода снижало защитные механизмы иммунного ответа, вызывая умеренную лейкопению и лимфопению у половозрелых полевок. Уменьшение количества тромбоцитов у самцов старшего возраста в ответ на холодовое воздействие представляется как целесообразная реакция организма, так как эти клеточные формы принимают непосредственное участие в репаративных процессах, необходимых при повреждении ткани холодом. Показатели красной крови (концентрация гемоглобина и содержание эритроцитов) оказались устойчивыми к кратковременному холодовому воздействию. Результаты, полученные в строго контролируемых условиях вивария на полевках-экономках, подтверждают, что воздействие низкой температуры даже непродолжительное время является стрессовым фактором для теплокровных животных. Планируется продолжить начатые исследования с применением холодовой нагрузки для выявления устойчивости клеток и тканей организма животных, обитающих в природной среде в условиях повышенного радиационного фона.

\section{Список литературы}

Абрашова Т.В., Гущин Я.А., Ковалева М.А., Рыбакова А.В., Селезнева А.И., Соколова А.П., Ходько С.В. 2013. Справочник. Физиологические, биохимические и биометрические показатели нормы экспериментальных животных. СПБ.: «ЛЕМА». $116 \mathrm{c}$.

Ажикова А.К., Журавлева Г.Ф. 2016. Исследование гематологических показателей крыс в норме и условиях термического воздействия // Современные проблемы науки и образования. № 2. http://scienceeducation.ru/ru/article/view?id=24350.

Алексахин Р.М., Архипов Н.П., Бархударов Р.М., Василенко И.Я., Дричко В.Ф., Иванов Ю.А., Маслов В.И., Маслова К.И., Никифоров В.С., Поликарпов Г.Г., Попова О.Н., Сироткин А.Н., Таскаев А.И., Тестов Б.В., Титаева Н.А., Февралева Л.Т. 1990. Тяжелые естественные радионуклиды в биосфере: Миграция и биологическое действие на популяции и биогеоценозы. М.: Наука. 368 с.

Бойко E.P. 2005. Физиолого-биохимические основы жизнедеятельности человека на Севере. Екатеринбург: Уро РАН. 189 с.

Васильева А.Н., Сынзыныс Б.И., Ульянова Л.П., Ковалев О.А., Сморызанова О.А., Старков О.В., Латынова Н.Е., Круглов С.В., Момот О.А., Козьмин Г.В. 2007. Оценка загрязнения биоценоза в районе размещения регионального хранилища радиоактивных отходов и его влияния на грызунов // Радиационная биология. Радиоэкология. Т. 45. № 5. С. $608-$ 615. 
Ватутин Н.Т., Ещенко Е.В. 2016. Лимфопения: основные причины развития. Архивъ внутренней медицины. № 2 (28). С. 22-27.

Гармаева Д.К., Аржакова Л.И., Дмитриева Т.И., Павлова Н.И., Гармаев Ц.К. 2019. Показатели клеточного состава крови при экспериментальном холодовом воздействии // Современные проблемы науки и образования. № 1. http://science-education.ru/ru/article/view?id=28441.

Горизонтов П.Д., Белоусова О.И., Федотова М.И. 1983. Стресс и система крови. М.: Медицина. 240 с.

Елифанов А. В., Гашев С.Н., Моисеенко Т. И. 2012. Влияние сырой нефти на организм грызунов в подостром эксперименте // Труды Карельского научного центра Российской академии наук. № 2. С. 76-83.

Жуков Д.А., Данилов О.А. 1995. Различие в реакции старых и молодых крыс на острый эмоциональный стресс // Журнал эволюционной биохимии и физиологии. Т.31. № 1. С. 92-102.

Залесская Г.А., Насек В.М., Зильберман Р.Д. 2018. Реакция периферической крови экспериментальных животных на комбинированное воздействие низкоинтенсивного лазерного и гамма-излучения // Весці Нацыянальнай акадэміi навук Беларусі. Серыя біялагічных навук. Т. 63. № 2. С. 201-208.

Иванов С.Д., Морозов В.И. 2018. Повышение радиорезистентности крыс после истощающих нагрузок: гематологические показатели // Радиационная биология. Радиоэкология. Т.58. № 1. С. 35-44.

Каракин Е.И., Дупал Т.А., Бочкарев М.Н., Иванов В.В. 1999. Биомониторинг природных популяций мышевидных грызунов (Rodentia) в контрастных по уровню антропогенных нагрузок районах Алтайского края: проблема создания адекватной тест-системы. // Информационный вестник ВОГИС. № 8. C.1-10.

Кудямева А.Г. 2016. Зависимости активности ферментов энергетического обмена у полевок от исходного уровня на действие холода // Содружество. 2016. № 4(4). С. 91-94.

Материй Л.Д., Ермакова О.В., Таскаев А.И. 2003. Морфофункциональная оценка состояния организма мелких млекопитающих в радиоэкологических исследованиях (на примере полевки-экономки). Сыктывкар. 164 с.

Прокопьев Н.П. 2014. Материалы по экологии полевки-экономки (Microtus oeconomus Pallas) в долине Туймаада средней Лены // Вестник СВФУ. Т 11. № 4. C. 21-28.

Раскоша О.В. 2018. Оценка устойчивости клеток щитовидной железы полевок-экономок, обитающих в разных радиоэкологических условиях после дополнительных воздействий, методом ДНК-комет // Известия Уфимского научного центра РАН. № 3(5). С. 5-11.

Раскоша О.В., Кичигин А. И. 2016. Основные принципы надлежащей лабораторной практики (НЛП, GLP) при обустройстве вивария и организации научных исследований // Вестник Института биологии Коми НЦ УрО РАН. №3. С. 19-25.

Соловьев В. С., Жевновская А.Н., Гашев С. Н., Соловьева С.В. 2016. Влияние электромагнитного излучения промышленной частоты на 
гематологические показатели периферической крови грызунов // Принципы экологии. № 2 (18). С. 84-90.

Солонин Ю.Г., Марков А.Л., Бойко Е.Р. 2011. Функциональные показатели здоровья у мужчин-северян // Известия Коми НЦ УрО РАН. №3 (7). С. 43 47.

СП 2.2.1.3218-14 «Санитарно-эпидемологические требования к устройству, оборудованию и содержанию экспериментально-биологических клиник (вивариев)»

Тарахтий Э.А., Мухачева С.В. 2016. Система крови лесных полевок (Cricetidae, Rodentia) в условиях промышленного загрязнения // Поволжский экологический журнал. № 2. С. 240-250.

Шаповалов К.Г., Михайличенко М.И., Сизоненко В.А. Функциональное состояние тромбоцитов при местных холодовых поражениях // Казан. мед. ж. 2008. Т. 89, № 5. С. 662-665.

Шилкова Т.В., Шибкова Д.З., Ефимов Н.В., Полевик Н.Д. 2011. Оценка биологических эффектов электромагнитного поля радиочастотного диапазона низкой интенсивности на систему крови экспериментальных животных // Вестник ЮУрГУ. № 7. С. 10-14.

World Medical Association Declaration of Helsinki: Ethical Principles for Medical Research Involving Human Subjects. UMS. 2002. P. 42-46.

Xy GZ, Ян SJ, Xy WX, Вэнь Z, Не D, Цзэн LF, Сян $Q$, Ву XM, Чжоу WY, Чжу $Q X$. 2016. The effect of cold stress on the immune system in rats // Exp Ther Med. №11 (1). P. 33-42.

\title{
EFFECTS OF SHORT-TIME COLD IMPACT ON HEMATOLOGIC CHRARCTERISTICS OF TUNDRA VOLE (MICROTUS OECONOMUS PALLAS)
}

\author{
A.G. Kudyasheva, A.V. Ermakova, O.V. Raskosha \\ Institute of Biology FRC Komi SC UrD RAS, Syktyvkar
}

We studied the effect of the 2-hours exposure to the low temperature $\left(-50^{\circ} \mathrm{C}\right)$ on the hematological parameters of male tundra vole (Microtus oeconomus Pallas) of different ages (2, 4, and 10 months). We found the relation of the effect on the age of the animals. Voles of the older age group responded to a higher degree to general hypothermia. The action of the cold causes moderate leukopenia and lymphopenia in mature animals (4 and 10 months), as well as a decrease in platelet content in peripheral blood in 10month-old males. The data obtained indicate the sensitivity of the peripheral blood indices of male tundra voles to the short-term effect of low temperature. They are a reflection of non-specific cellular reactions.

Keywords: coldness, non-specific reaction, stress, periphery blood, tundra vole, age. 


\section{Об авторах:}

КУДЯШЕВА Алевтина Григорьевна - доктор биологических наук, ведущий научный сотрудник отдела радиоэкологии, Институт биологии Федеральный исследовательский центр Коми научного центра УрО РАН, 167982, Сыктывкар, 28, ул. Коммунистическая, д. 28, e-mail: kud@ib.komisc.ru.

ЕРМАКОВА Анастасия Владимировна - аспирант, старший лаборант-исследователь отдела радиоэкологии, Институт биологии Федеральный исследовательский центр Коми научного центра УрО PAH, 167982, Сыктывкар, 28, ул. Коммунистическая, д. 28, e-mail: ermakova_a.v@ib.komisc.ru

РАСКОША Оксана Вениаминовна - кандидат биологических наук, старший научный сотрудник отдела радиоэкологии, Институт биологии Федеральный исследовательский центр Коми научного центра УрО РАН, 167982, Сыктывкар, 28, ул. Коммунистическая, д. 28, e-mail: raskosha@ib.komisc.ru.

Кудяшева А.Г. Влияние кратковременного холодового воздействия на гематологические показатели полевки-экономки (Microtus oeconomus Pallas) / А.Г. Кудяшева, А.В. Ермакова, О.В. Раскоша // Вестн. ТвГУ. Сер. Биология и экология. 2020. № 2(58). С. 55-63.

\section{БОТАНИКА}

УДК 581.4+581.5 (470.1)

ЭКОЛОГИЧЕСКАЯ МОРФОЛОГИЯ SAXIFRAGA HIRCULUS L. 